OPEN ACCESS

Edited by:

Farhad Ravandi,

University of Texas MD Anderson

Cancer Center, United States

Reviewed by:

Nadim Mahmud,

University of Illinois at Chicago,

United States

Michael Diamantidis,

University Hospital of Larissa, Greece

*Correspondence:

Uday Kulkarni

kulkarni.uday@cmcvellore.ac.in

Specialty section:

This article was submitted to Hematologic Malignancies,

a section of the journal

Frontiers in Oncology

Received: 26 October 2020

Accepted: 11 January 2021

Published: 25 February 2021

Citation:

Kulkarni U and Mathews V (2021)

Evolving Chemotherapy Free

Regimens for Acute

Promyelocytic Leukemia.

Front. Oncol. 11:621566.

doi: 10.3389/fonc.2021.621566

\section{Evolving Chemotherapy Free Regimens for Acute Promyelocytic Leukemia}

\author{
Uday Kulkarni ${ }^{*}$ and Vikram Mathews \\ Department of Haematology, Christian Medical College \& Hospital, Vellore, India
}

With the treatment advances over the last three decades, acute promyelocytic leukemia (APL) has evolved from being the most malignant form of acute leukemia to a leukemia with excellent long term survival rates. In the present review, we have summarized data leading to the development of the currently used treatment regimens for APL, which incorporate either none or minimal chemotherapeutic drugs. We have discussed the historical aspects of APL treatment along with the challenges associated with chemotherapy-based approaches and our experience with the use of single agent arsenic trioxide (ATO) which was one of the first successful, non-chemotherapy approaches used for APL. Subsequently, we have reviewed the data from major clinical trials in low-intermediate risk $\mathrm{APL}$ and high risk APL which guide the current clinical practice in APL management. With accumulating data on oral ATO, we postulate that the treatment for low-intermediate risk APL will be a completely oral ATO + ATRA regimen in the future. While for high-risk APL, we believe that minimal anthracycline use with ATO + ATRA might become the standard of care soon. A number of promising nonchemotherapy drugs with pre-clinical data would merit clinical testing in the high risk and relapsed setting, with potential to translate to a complete oral chemotherapy free combination regimen in combination with ATO and ATRA.

\footnotetext{
Keywords: differentiation therapy, arsenic trioxide, acute promyelocytic leukemia, all-trans retinoid acid (ATRA), non-chemotherapeutic treatment
}

\section{INTRODUCTION}

Acute promyelocytic leukemia (APL) is a distinct form of acute myeloid leukemia (AML) characterized by $\mathrm{t}(15 ; 17)$, a reciprocal translocation leading to a fusion transcript PML-RARA. This leads to a block in differentiation of the leukemic cells at the stage of promyelocytes.

APL was first described in 1957 by a Norwegian physician in a case series involving three patients, all of whom were treated with steroids and died. It was noted that APL has a very rapid fatal course and has a severe bleeding tendency making it the "most malignant form of acute leukemia" (1). Subsequently, daunorubicin was noted to result in remission in almost $70 \%$ patients with median remission duration of about 2 years. The responses and survival rates, at those times, were similar to those in other patients with a diagnosis of AML $(2,3)$. However, unique to this subtype of AML was the exacerbation of a coagulopathy, associated with fatality in a proportion of cases, after initiation of chemotherapy (4). 


\section{All-Trans Retinoic Acid}

The advent of all-trans retinoic acid (ATRA) has revolutionized the treatment in APL with high complete remission (CR) rates without myelosuppression, reduced length of hospitalization, dramatic reduction in coagulopathy, reduced transfusion requirements, and reduction in early treatment related mortality (5). However, despite high CR rates, none of the patients were cured with single agent ATRA (6). It was subsequently demonstrated through a series of landmark studies that a combination of chemotherapy and ATRA used upfront during induction, along with a risk-adapted consolidation approach resulted in excellent long-term survival rates exceeding $80 \%$ (7-11).

\section{Arsenic Trioxide}

The single most potent therapy for APL both in relapsed as well as upfront therapy for APL is arsenic trioxide (ATO) $(12,13)$. Historically, arsenic compounds have been used for treating various ailments, like chronic myeloid leukemia, trypanosomiasis, and dermatological conditions including syphilis (14). In China, at the Harbin Medical University, "Ai ling No 1", an arsenic-based traditional Chinese recipe, was evaluated methodically for its therapeutic role in various malignancies (15). This preparation was called 713 (for the year and month of the initiation of this study). They studied more than 1,000 patients with various malignancies and noted that this preparation was maximally beneficial for the treatment of patients with APL. Subsequent studies also confirmed these observations (4). Single agent ATO was shown to result not only in excellent CR rates but also that these remissions were durable, in patients with APL relapsing after ATRA+chemotherapy (12). The dose used was $10 \mathrm{mg}$ daily for adults till achievement of CR. This dose was derived from experience with the doses used in Chinese native medicines and not formal Phase I clinical trials. Subsequently, it was found that ATO was active in APL in doses ranging from $0.06 \mathrm{mg} / \mathrm{kg}$ to 0.2 $\mathrm{mg} / \mathrm{kg}$ and that a dose of $0.15 \mathrm{mg} / \mathrm{kg} /$ day can be used in children (16). Various strategies for treating APL incorporating ATO include: upfront use of single agent ATO, use of ATO after achieving remission with ATRA+chemotherapy, use of ATO +ATRA induction followed by chemotherapy consolidation, and use of ATO+ATRA and chemotherapy in induction (17). The longterm cure rates with a combination of ATO and ATRA in lowintermediate risk APL have exceeded 90\%-95\%, and hence this forms the current standard of care for treating low-intermediate risk APL $(18,19)$.

\section{Need for Non-Chemotherapy Approaches}

Elimination of cytotoxic chemotherapy has potential advantages of reduction in myelosuppression and resulting infections and bleeding, reduction in early risk of hemorrhagic events partly attributed to release of procoagulants after destruction of APL cells, and reduction in risk of long-term complications like cardiotoxicity and secondary myeloid neoplasms (17). Additionally, the health resource utilization and treatment costs are also significantly lower with non-chemotherapy approaches in APL (20). This is of particular significance for low-middle income countries wherein the resources are limited and there is an increasing burden of antimicrobial drug resistance.

\section{OUR EARLY EXPERIENCE WITH NON- CHEMOTHERAPY REGIMEN-SINGLE AGENT ATO}

At our institution, two patients with APL who relapsed following chemotherapy (one of them also received ATRA) were advised palliative care. They subsequently chose to take alternative medications containing arsenic (Ayurvedic preparation from Vaidya Balendu Prakash at Dehradun, India) and went into durable remissions. They were administered this preparation continuously and in one case, this was continued beyond 5 years. Of these, one was noted to have severe arsenic keratosis and subsequently died of secondary squamous cell carcinoma $(4,21)$.

Following this, treatment with single agent ATO for APL was evaluated in the setting of a clinical trial since 1998 at our center. Our hospital pharmacy manufactured the intravenous ATO inhouse with appropriate quality control measures. This manufacturing process was subsequently transferred to the industry in the year 2001 (Intas Pharmaceuticals Ltd, Matoda, Gujarat, India). We demonstrated that single agent ATO led to durable remissions in newly diagnosed APL with 5-year overall survival of $74.2 \pm 5.2 \%$. The toxicity profile was acceptable with mild reversible toxicity in the majority. There were no sudden cardiac deaths or acute hepatic failure. There were no long-term toxicities in terms of cardiac dysfunction or second malignancies. Additionally, seven patients in our cohort attained normal parenthood after completing ATO treatment (22-24).

In addition to efficacy and safety data, we also reported the pattern of leukocyte recovery following single agent ATO therapy in APL. With ATO treatment, about $1 / 3^{\text {rd }}$ patients have initial prolonged leukopenia followed by gradual normalization of the counts while the remaining $2 / 3^{\text {rd }}$ patients have an initial leukocytic response. We used hydroxyurea (or anthracycline if WBC counts increased despite hydroxyurea) to manage the leukocytosis. The leukocytosis is usually followed by a leukopenic phase of variable duration following which there is recovery to normal WBC counts (21). We reported, for the first time, that FLT3 activating mutations and secondary cytogenetic changes were not associated with an adverse impact on clinical outcome in APL treated with ATO $(23,25)$.

We also studied the arsenic levels in hair and nail samples of patients and control subjects. We noted no significant difference in the arsenic retention between controls and patients who had completed treatment at least 2 years ago. Also, immediately at the end of treatment, the arsenic levels were less than the lower limit of the normal range defined by the Agency for Toxic Substances and Disease Registry (ATSDR), Atlanta, Georgia (24).

\section{VARIOUS STRATEGIES OF USING ATO IN APL}

Upfront use of single agent ATO has been shown to result in excellent long term survival rates in patients having WBC counts less than $5 \times 10^{9} / \mathrm{L}$ and platelet count $>20 \times 10^{9} / \mathrm{L}$, whereas 5 year overall survival for the high risk patients was $63 \%$ (24). Also 
multiple courses of ATO consolidation after single agent ATO induction has been shown to improve the disease-free survival in APL (26).

In the North American Leukemia Intergroup study C9710, addition of ATO in consolidation following ATRA + chemotherapy induction, resulted in improved event-free survival ( $80 \%$ versus $63 \%$ at 3 years, p 0.001 ) however the overall survival was similar ( $86 \%$ versus $81 \%$ at 3 years, $p$ 0.059) (27).

Pre-clinical studies showed synergy between ATO and ATRA both in in vitro experiments with APL cell lines as well as in animal model experiments with a possible benefit of sequential therapy over concurrent treatment. These have further formed the rationale for early clinical studies using the chemotherapy free combination of ATO and ATRA $(28,29)$.

A combination of ATO and ATRA used during induction followed by chemotherapy-based consolidation has been shown to be better than either agent used alone in terms of the time to $\mathrm{CR}$, time to platelet recovery, fold change in the PML-RARA transcripts and also the long-term relapse risk (30).

Use of ATO-ATRA along with idarubicin during induction followed by ATO+ATRA consolidation and maintenance with ATRA/6-Mercaptopurine/Methotrexate resulted in excellent long-term survival exceeding $90 \%$ in the Australian APML4 study, with reduction in anthracycline exposure to a large extent (31).

\section{LOW AND INTERMEDIATE RISK APL}

Low-intermediate risk APL is defined as APL with initial white blood cell count $\left.\leq 10 \times 10^{9} / \mathrm{L}\right)(32)$. Randomized clinical trials (GIMEMA-AMLSG-SAL APL0406 and UK NCRI AML17) have demonstrated the superiority of combination therapy with ATO and ATRA (ATO + ATRA) over conventional therapy with ATRA and chemotherapy (ATRA + chemotherapy) in lowintermediate risk APL $(18,19)$.

\section{APL0406 (ClinicalTrials.gov Identifier: NCT00482833)}

In the APL0406 trial, with the median follow-up being 40.6 months, treatment with ATO + ATRA resulted in significant improvement in the overall survival in patients with lowintermediate risk APL as compared to ATRA + chemotherapy treatment $(99.2 \%$ versus $92.6 \%$ at 50 months, $\mathrm{p}=0.0073)$. The updated results from the APL0406 study showed an increasing benefit over time with ATO + ATRA as compared to ATRA + chemotherapy. At a median follow up of 66.4 months, the 6-year event-free survival was significantly better with ATO + ATRA as compared to ATRA + chemotherapy $(96.6 \%$ versus $77.4 \%, \mathrm{p}$ 0.0002). The cumulative incidence of relapse was significantly lower with ATO + ATRA as compared to ATRA + chemotherapy ( $1.7 \%$ versus $15.5 \%, \mathrm{p} 0.02)$.

The proportion of patients with grade 3-4 thrombocytopenia and neutropenia for more than 15 days, those with infections and fever of unknown origin, and those with grade 3-4 gastrointestinal toxicity was lower with ATO + ATRA as compared to ATRA + chemotherapy. The proportion of patients with grade 3-4 hepatotoxicity and QTc prolongation during induction, and those with all grades of neurotoxicity during consolidation was greater with ATO + ATRA as compared to ATRA + chemotherapy. The toxicity resolved in all patients with temporary discontinuation of therapy except one patient who required ATO's permanent discontinuation. During induction, there were four deaths in the ATRA + chemotherapy group (1 cardiovascular, 1 ARDS, 1 ischemic stroke, and 1 respiratory disease) with none in the ATO + ATRA group. Post-induction, there were five deaths while in remission in the ATRA + chemotherapy group, of which two had therapy-related myeloid neoplasm, while two died while in remission in the ATO + ATRA group of which one had colon carcinoma. Additionally, there were four deaths due to relapse in the ATRA + chemotherapy group $(19,33)$.

\section{UK NCRI AML17 (International Standard Randomized Controlled Trial Number ISRCTN55675535)}

The UK NCRI AML17 trial primarily looked at the quality of life measured using the European Organization for Research and Treatment of Cancer (EORTC) QLQ-C30 global health status in APL patients treated with ATO + ATRA versus ATRA + chemotherapy. They had used an attenuated ATO schedule with ATO $0.3 \mathrm{mg} / \mathrm{kg}$ IV for 5 days in week 1 followed by 0.25 $\mathrm{mg} / \mathrm{kg}$ IV twice a week from week 2 onward during both induction and consolidation in variance with the daily ATO used in APL0406 trial (Table 1). They did not report a significant difference in the quality of life between the patients treated in the two groups studied. In fact, for cognitive and role functioning domains, significant benefits were recorded in favor of ATO + ATRA. Most patients (93\%) with high risk APL in the ATO + ATRA group received gemtuzumab ozogamicin. In the updated results from the AML17 trial, at a median follow-up of 67.4 months, frank relapses were significantly lower with ATO (1\% versus $5 \%$ at 5 years, $\mathrm{p} 0.005$ ) resulting in improved relapse-free survival irrespective of the risk group (for low risk 95\% versus $87 \%$, p 0.3 , while for high risk $100 \%$ versus $83 \%$, p 0.03 ).

The 60-day mortality was similar with ATRA + chemotherapy and ATO + ATRA ( $9 \%$ versus $5 \%, p$ 0.22). The causes of death in the ATO + ATRA group were: 3 cardiac events, 1 renal failure, 1 infection, and 1 due to several causes, while for 11 patients in the ATRA + chemotherapy group were: 3 hemorrhages, 3 infections, 2 pulmonary causes, 1 renal cause, and 2 progressive disease. The incidence of therapy-related myeloid neoplasm was $6 \%$, with no case seen after ATO + ATRA. Of 32 patients (including 17 with a molecular relapse) who relapsed on ATRA + chemotherapy group, 31 patients attained molecular CR with ATO and had 5 year survival of $88 \%$ with a median follow-up of 44.9 months. The highly effective salvage therapy with ATO and minimal residual disease monitoring resulted in a lack of overall survival benefit between the two arms of the AML17 trial in variance with the APL0406 trial. Hyperbilirubinemia, cardiac events, gastrointestinal events, and alopecia were more frequent in the ATRA + chemotherapy arm during treatment course 1 . The proportion of 
APL0406 (low-

UK AML 17 (all risk intermediate risk)

$(19,33)$

ATO+ATRA arm

APL0406 (low-

intermediate risk)

$(19,33)$

ATRA+CHT arm groups) (18, 34)

ATO+ATRA arm

$\mathrm{PO}-$ maximum of 60 days (median

Idarubicin $12 \mathrm{mg} / \mathrm{m}^{2}$ IV on days $2,4,6$ and 8 along with daily ATRA $45 \mathrm{mg} / / \mathrm{m}^{2}$ $\mathrm{PO}$ for up to 60 days

K AML 17 (all risk groups) $(18,34)$

ATRA+CHT arm

APML4 study (All risk groups) (35)

MDACC (All risk groups) $(36,37)$

SWOG 0535 (high risk) (38) followed by $0.25 \mathrm{mg} / \mathrm{kg}$ twice a week for week 2 to 8 .ATRA $45 \mathrm{mg} / \mathrm{m} 2 \mathrm{PO}$ daily up to 60 days $\mathrm{GO} 6 \mathrm{mg} / \mathrm{m} 2$ single dose within 4 days for high risk. and 8 along with daily ATRA $45 \mathrm{mg} / \mathrm{m} 2$ $\mathrm{PO}$ for up to 60 days 2, 4, 6, and 8 ATO $0.15 \mathrm{mg} / \mathrm{kg}$ IV days 9 to 36 $\mathrm{PO}$ - till CR (medion of 30 d

1 in case of high risk

ATO $0.15 \mathrm{mg} / \mathrm{kg}$ IV + ATRA $45 \mathrm{mg} / \mathrm{m} 2$ $\mathrm{PO}$ - till CR (median of 39.5 days) GO time to $C R-32$ days)
ATO $0.15 \mathrm{mg} / \mathrm{kg}$ IV + ATRA $45 \mathrm{mg} / \mathrm{m}^{2}$

ATO $0.15 \mathrm{mg} / \mathrm{kg}$ IV for 5 days per week, 4 weeks on 4 weeks off, for 4 courses and ATRA $45 \mathrm{mg} / \mathrm{m}^{2} \mathrm{PO}$ daily 2 weeks on and 2 weeks off, for 7 courses

Idarubicin $5 \mathrm{mg} / \mathrm{m} 2 /$ day IV for days 1 to 4 (first cycle), mitoxantrone $10 \mathrm{mg} / \mathrm{m} 2 /$ day IV on days $1-5$ (second cycle) and idarubicin day 1 to day 15 during each consolidation cycle.

Maintenance - 6-MP 50mg/m2/day, MTX 15mg/m2/week alternating with ATRA $45 \mathrm{mg} / \mathrm{m} 2 /$ day given for 15 days every 3 months

ATO $0.3 \mathrm{mg} / \mathrm{kg}$ IV for 5 days in week 1 Course 2 to 5 : ATO $0.3 \mathrm{mg} / \mathrm{kg}$ IV for 5 days in week 1 followed by

Idarubicin $12 \mathrm{mg} / \mathrm{m} 2 \mathrm{IV}$ on days 2,4, 6, Idarubicin $5 \mathrm{mg} / \mathrm{m} 2 /$ day for days 1 to 4 (first cycle), mitoxantrone

$10 \mathrm{mg} / \mathrm{m} 2 /$ day on days $1-5$ (second cycle) and idarubicin $12 \mathrm{mg} / \mathrm{m} 2$ on day 1 (third cycle). ATRA $45 \mathrm{mg} / \mathrm{m} 2 /$ day from day 1 to day 15 during each consolidation cycle.

ATRA $45 \mathrm{mg} / \mathrm{m} 2$ days $1-36$. Idarubicin ATRA $45 \mathrm{mg} / \mathrm{m} 2$ and ATO $0.15 \mathrm{mg} / \mathrm{kg}$ IV from day 1 to 28 in cycle $12 \mathrm{mg} / \mathrm{m} 2$ for age 1 to 60 years on day 1 . ATRA $45 \mathrm{mg} / \mathrm{m} 2$ on days $1-7,15-21,29-35$ and ATO $0.15 \mathrm{mg} /$

$\mathrm{kg}$ IV 5 days in a week for 5 weeks in cycle 2 .

8 cycles of maintenance: ATRA $45 \mathrm{mg} / \mathrm{m} 2$ days $1-14$ along with MTX 5-15mg/ $\mathrm{m} 2$ and 6-MP 50-90 mg/ $\mathrm{m} 2$ on days $15-90$.

ATO $0.15 \mathrm{mg} / \mathrm{kg} \mathrm{IV} \mathrm{+} \mathrm{ATRA} 45 \mathrm{mg} / \mathrm{m} 2$ ATO $0.15 \mathrm{mg} / \mathrm{kg}$ IV 5 days per week, 4 weeks on 4 weeks off, for ATO $0.15 \mathrm{mg} / \mathrm{kg}$ IV 5 days per week, 4 weeks on 4 weeks off, for
4 courses and ATRA $45 \mathrm{mg} / \mathrm{m} 2 \mathrm{PO}$ daily 2 weeks on and 2 weeks $9 \mathrm{mg} / \mathrm{m} 2$ or Idarubicin $12 \mathrm{mg} / \mathrm{m} 2$ on day off for 7 courses $9 \mathrm{mg} / \mathrm{m} 2$ on day 1 $12 \mathrm{mg} / \mathrm{m} 2 \mathrm{IV}$ on day 1 (third cycle). ATRA $45 \mathrm{mg} / \mathrm{m} 2 /$ day PO from
ATO $0.15 \mathrm{mg} / \mathrm{kg}$ IV for 25 days (Cycle 1 and 2). Daunorubicin $50 \mathrm{mg} / \mathrm{m} 2$ for 3 days and ATRA $45 \mathrm{mg} / \mathrm{m} 2$ for 7 days (cycle 3 and 4 ) and GO $9 \mathrm{mg} / \mathrm{m} 2$ on day 1 (cycle 5 and 6) Maintenance 1 year : ATRA $45 \mathrm{mg} / \mathrm{m} 2$ for 7 days (every 14 days) with $6-\mathrm{MP} 60 \mathrm{mg} / \mathrm{m} 2$ and
No induction deaths; 2

At 50 months, OS of $99.2 \%$ post induction

4 deaths during induction and 5 while in remission post induction 95\%Cl: 87.9 to 97.5 Therapy related myeloid

neoplasms - none

60 -day mortality - 9\%;

Therapy related myeloid

neoplasms $-6 \%$

Early death rate - 3.2\%; No therapy related myeloid neoplasm

Induction mortality - 4\%

6 -week mortality - 11\%
60 -day mortality - 5\%, 5-year OS 92\%

5-year OS 86\%

5-20ar Os 96\% (95\% 99) for low-intermediate risk and $87 \%$ (95\%Cl: 65-96) for high risk

5 year OS 89\% for low risk and $86 \%$ for high risk

$16.5 \mathrm{mg} / \mathrm{kg}$ ATO $12 \mathrm{mg} / \mathrm{m} 2$ idarubicin

3 year OS of $86 \%(95 \% \mathrm{Cl}$ : 75 to 92$)$

$300 \mathrm{mg} / \mathrm{m} 2$

daunorubicin

$80 \mathrm{mg} / \mathrm{m} 2$ of $50 \mathrm{mg} / \mathrm{m} 2$ of mitoxantrone $12.15 \mathrm{mg} / \mathrm{kg}$ ATO $48 \mathrm{mg} / \mathrm{m} 2$ of darubicin 
patients with high alanine transaminase (ALT) levels between the two groups was similar. After treatment course 1, the grade 3-4 ALT elevation was more common with ATO + ATRA than ATRA + chemotherapy (20\% grade 3 and $5 \%$ grade 4 versus $8 \%$ grade 3 and $2 \%$ grade 4 ). After course 2, liver toxicities did not differ between the 2 groups while cardiotoxicity was more frequent with ATO + ATRA (7\% grade $1-2,3 \%$ grade 3 , and none grade 4 ). Treatment discontinuation was required for 2 patients on ATO+ ATRA while on induction and for 6 while on consolidation (as per clinician's decision, with 2 having QTc prolongation). ATO + ATRA was associated with lesser days of hospitalization, lower transfusion, and intravenous antibiotic requirement as compared to ATRA + chemotherapy during the first two courses of therapy $(18,34)$.

\section{HIGH RISK APL}

High risk APL is defined as APL with initial white blood cell count $\left.>10 \times 10^{9} / \mathrm{L}\right)(32)$. In high-risk APL, broadly two approaches-either with minimal anthracycline use during induction or with the use of gemtuzumab ozogamicin, have been combined with ATO + ATRA.

\section{APML4 Study (Australian New Zealand Clinical Trials Registry, number ACTRN12605000070639)}

The APML4 study was a non-randomized phase 2 trial which looked at the freedom from relapse and early death with the addition of ATO to ATRA and idarubicin in induction with an ATO + ATRA consolidation. Thus, there was minimal use of anthracycline limited to induction therapy alone. However after two cycles of consolidation, patients received maintenance therapy with ATRA, 6-mercaptopurine, and methotrexate for 2 years. The results were compared with that of the earlier APML3 study which had excluded ATO. The early death rate was lower (3.2\% versus $7.1 \%)$ however this did not achieve statistical significance. Among the 124 patients studied, 23 were high risk as per the Sanz risk stratification. Among the high risk patients, on comparison with the APML3 results, the freedom from relapse was significantly better (2-year rate of $95 \%$ versus $69 \%$; $p$ 0.024) however the overall survival was similar (2-year OS $87 \%$ versus $87 \%$; p 0.40 ). For high risk disease, the cumulative incidence of relapse was $5 \%$ at 5 years compared to $31 \%$ at 2 years in the APML3 study. Also there were no deaths in remission during consolidation. There were no instances of secondary myelodysplasia or leukemia reported (35).

\section{Gemtuzumab Ozogamicin}

Addition of gemtuzumab ozogamicin (GO) to the combination of ATO + ATRA in induction is a promising approach which has been evaluated in multiple studies (36-38). In the MD Anderson Cancer Center (MDACC) trial (ClinicalTrials.gov Identifier: NCT01409161), of the 187 patients studied, 54 were high risk. The induction mortality was $4 \%$. The CR rate in low risk as well as high risk patients was $96 \%$ with a median time for attaining CR of 30 (17-80) days. Among the 54 high risk patients, 45 received GO $9 \mathrm{mg} / \mathrm{m}^{2}$ on day 1 while the remaining received idarubicin $12 \mathrm{mg} / \mathrm{m}^{2}$ on day 1 due to lack of availability of GO. The 5-year EFS and OS for the high risk group was $81 \%$ and $86 \%$ respectively. Five patients with high risk disease developed disease relapse. Treatment related adverse events included hepatotoxicity grade 3 and above in $14 \%$ patients and infections grade 3 and above in $23.5 \%$ patients.

Similarly, as mentioned earlier in the UK NCRI AML17 study GO was added to ATO+ATRA in the high risk subset and was associated with a $100 \%$ relapse-free survival, however the study was not powered to address efficacy in this subset.

In the SWOG study (ClinicalTrials.gov Identifier: NCT00551460), patients with high risk APL were treated with ATO + ATRA and GO in induction, followed by consolidation with two cycles of ATO, two cycles of ATRA with chemotherapy (daunorubicin) and two cycles of GO. They also included 1 year of maintenance with ATRA, 6-mercaptopurine, and methotrexate. They studied 70 patients with high risk APL. The 6-week mortality rate was $11 \%$ and $86 \%$ patients achieved CR at the end of induction. Treatment related adverse events during induction included about elevated liver enzymes grade 3 and above in $16 \%$ patients and infections grade 3 and above in 20\%. The 3 year EFS was $78 \%$ (95\% confidence interval: $67 \%$ to $86 \%$ ). About $37 \%$ patients in remission were not able to complete the planned post-remission therapy including $12 \%$ due to adverse events.

\section{ORAL ATO}

Three oral formulations of ATO are being developed. One is a liquid formulation and has been shown to have comparable efficacy similar to IV ATO. The safety and efficacy of this formulation has been established in frontline setting given after ATRA and chemotherapy (39). The second one is oral arsenic realgar-Indigo naturalis formula (RIF) given as $60 \mathrm{mg} / \mathrm{kg}$ bodyweight daily. In non-high risk patients, this formulation is non-inferior to intravenous ATO with a similar adverse effect profile (40). Thirdly, ORH-2014 is another oral formulation for which pharmacokinetic and safety data is available (41).

\section{OTHER POTENTIAL NON- CHEMOTHERAPY OPTIONS IN APL}

\section{Targeting Microenvironment Mediated Resistance to ATO by Downregulating the NK- kB Pathway}

We have been using ATO-based therapy for upfront treatment of APL for the last two decades (24). We have shown that there is a significant contribution of microenvironment mediated resistance to ATO at relapse (42) and demonstrated the importance of the NF$\mathrm{kB}$ pathway in mediating this resistance. We further demonstrated a 
synergistic effect of bortezomib, a proteasome inhibitor which is known to downregulate the NF-kB pathway, and ATO in overcoming ATO resistance in pre-clinical studies. This synergy is due to downregulation of the NF-kB pathway, increased generation of reactive oxygen species in malignant cells, and an increased unfolded protein response. Since ATO is known to cause PMLRARA degradation through the proteasome, a theoretical concern with the use of a proteasome inhibitor with ATO was that whether the proteasome inhibitor would inhibit the degradation of the PMLRARA oncoprotein. However, we noted that with the combination of ATO and bortezomib, the PML-RARA oncoprotein is cleared through an alternative p62-dependent autophagy pathway (43). This work has been translated to a phase 2 clinical trial for relapsed APL wherein we have demonstrated that a combination of ATO, ATRA, and anthracycline with the addition of bortezomib is safe (44) (Figure 1).

\section{Targeting Epigenetic Resistance to ATRA by Activating MEK/ERK Signaling}

Drug resistance to ATRA is mediated by mutations in the ligand binding domain of PML-RARA or epigenetic modifications in the RARA promoter preventing expression of genes targeted by retinoic acid. The permissiveness of the RAR promoter is restored by activating the MEK/ERK signaling pathway (45).

It has also been demonstrated that the in vitro resistance to ATRA in APL cell lines can be overcome by use of glycogen synthase kinase-3beta inhibitors including lithium chloride by restoring ATRA-induced differentiation. This effect is abolished by inhibition of the MEK/ERK1/2 pathway. In in vivo mouse models, lithium chloride combined with ATRA resulted in a significant survival advantage as compared to ATRA alone (46).

\section{Targeting Energy Metabolism and Anti- Apoptotic Pathways}

We have previously shown that there exists a significant change in the energy metabolism pathways in APL cell lines resistant to ATO (47). This forms a rationale for targeting APL with energy metabolism inhibitors.

The vitamin E derivative (+) $\alpha$-tocopheryl succinate acts by inhibiting the mitochondrial respiratory chain complex I. It exerts pro-apoptotic effects in various tumors. In a mouse model of APL, this compound has been shown to be as effective as ATO or ATRA (48).

Also, targeting anti-apoptotic pathways can be potentially explored in APL. In fact, primary APL samples have been shown to be significantly more sensitive to venetoclax than non-APL AML samples (49). The therapeutic role of mitocans, such as venetoclax, in APL remains to be explored.

\section{Synergistically Enhancing Differentiation}

Valproic acid also has been shown to induce differentiation in APL and has synergy with ATRA in preclinical models (50). Also, 1alpha, 25-dihydroxyvitamin D3 and vitamin K2 derivatives have been shown to augment retinoic acid induced differentiation of APL cell lines $(51,52)$.

\section{WAY FORWARD}

Table 1 summarizes the major clinical trials in APL which have explored treatment approaches either without or with minimal chemotherapy. Non-chemotherapy approach consisting of ATO + ATRA is the current standard of care for treating low-

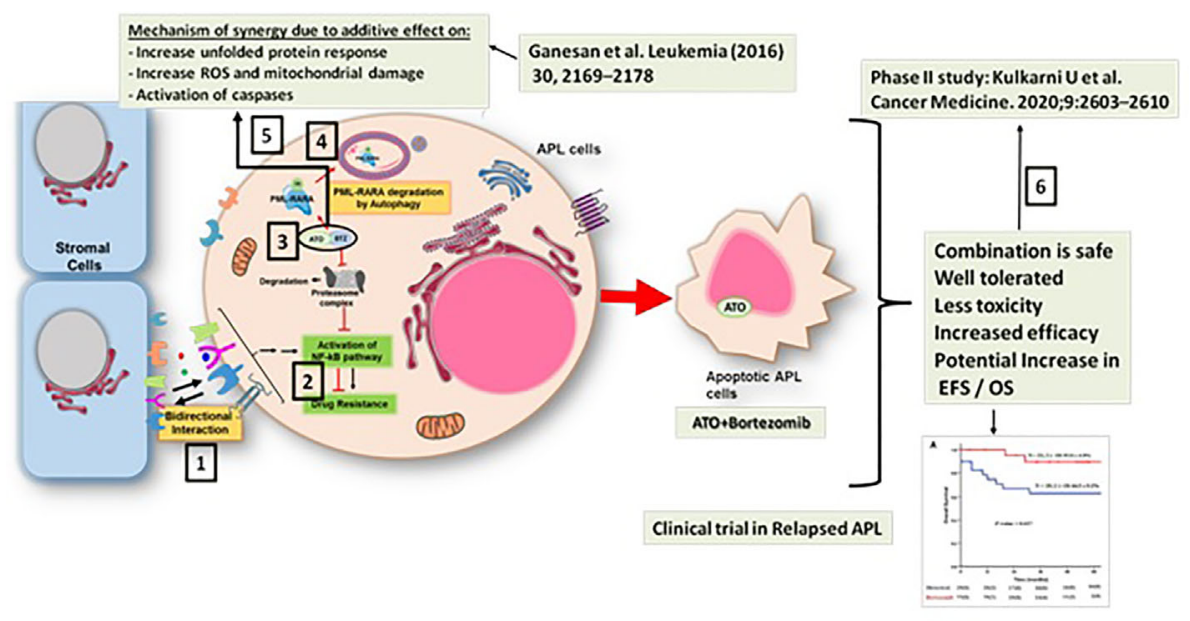

FIGURE 1 | Synergy between arsenic trioxide (ATO) and bortezomib in the treatment of acute promyelocytic leukemia. 1. There is a significant contribution of microenvironment mediated resistance to ATO at relapse (41). 2. This resistance is mediated predominantly by the NF-kB pathway (41). 3. Preclinical studies show a synergistic effect of bortezomib and ATO in overcoming ATO resistance (42). 4. With the combination of ATO and bortezomib, the PML-RARA oncoprotein is cleared through a p62-dependent autophagy pathway (42). 5. The mechanism of the synergy between ATO and bortezomib involved downregulation of the NF-kB pathway, increased unfolded protein response, and an increased generation of reactive oxygen species in the malignant cell (42). 6 . This work has been translated to a phase 2 clinical trial for relapsed APL wherein we have demonstrated that the combination of ATO, ATRA, and anthracycline with the addition of bortezomib is safe (43). 
TABLE 2 | Anticipated treatment algorithm for APL in future.

\begin{tabular}{|c|c|c|}
\hline $\begin{array}{l}\text { Treatment } \\
\text { phase }\end{array}$ & Low-intermediate risk APL & High risk APL \\
\hline Induction & $\begin{array}{l}\text { Oral ATO + oral ATRA } \\
\text { Dose and schedule optimization and } \\
\text { possible addition of other non- } \\
\text { chemotherapy agents to further } \\
\text { reduce cumulative dose of ATO and } \\
\text { ATRA and their side effects }\end{array}$ & $\begin{array}{l}\text { Oral ATO + oral ATRA + either of the following: } \\
\text { - } \quad \text { Minimal anthracycline, } \\
\text { - } \quad \text { Gemtuzumab ozogamicin (targeting high CD33 expression on APL cells), } \\
\text { - Bortezomib (targeting microenvironment mediated ATO resistance via NF-kB signaling), potential for } \\
\text { - } \quad \text { potent oral proteasome inhibitors to be evaluated here } \\
\text { Glycogen synthase kinase -3beta inhibitors like lithium chloride (targeting epigenetic modification of the } \\
\text { - } \quad \text { RARA promoter via MEKKERK signaling), } \\
\text { - Vitamin E or venetoclax (targeting energy metabolism or anti-apoptotic pathways), } \\
\text { Valproic acid or 1alpha, 25-dihydroxyvitamin D3 (synergistic differentiating activity with ATRA) }\end{array}$ \\
\hline Consolidation & Oral ATO + oral ATRA & Oral ATO + oral ATRA \\
\hline
\end{tabular}

(APL, acute promyelocytic leukemia; ATO, arsenic trioxide; ATRA, all-trans retinoic acid).

intermediate risk APL based on evidence from randomized clinical trials. For high risk disease, the TUD-APOLLO-064 randomized controlled trial is evaluating ATO + ATRA + idarubin-based induction regimen for high risk APL patients with ATO + ATRA consolidation as post-remission strategy with event-free survival as the primary outcome and standard AIDA regimen as the comparator. The results of this study are expected in the near future and are eagerly awaited.

Table 2 shows the anticipated treatment algorithm for APL in the future. With long term safety and efficacy data with oral ATO, we could possibly have a completely oral regimen of ATO + ATRA for low-intermediate risk APL. For high risk APL, if randomized data (TUD-APOLLO-064, ClinicalTrials.gov Identifier: NCT02688140) show superiority over conventional AIDA regimen, ATO + ATRA with minimal anthracycline use could be the standard therapy in the near future as shown in the anticipated treatment algorithm in Table 2. Other potential drugs that can be explored in the setting of high risk or relapsed disease have been shown in Table 2. Targeting microenvironment mediated drug resistance via the NF-kB signaling using bortezomib is an approach which we are currently exploring $(43,44)$. Combining glycogen synthase kinase-3beta inhibitors like lithium chloride with ATRA for targeting epigenetic mechanisms of resistance to ATRA via MEK/ERK signaling is another interesting approach. Also, lithium chloride is known to induce autophagy which is also a key component of ATRA induced differentiation in APL $(46,53)$. Targeting energy metabolism and antiapoptotic pathways using drugs like vitamin $\mathrm{E}$ and venetoclax respectively also could have potential therapeutic significance in high risk or relapsed APL, as could agents like vitamin D and Valproic acid showing synergy in differentiation in APL (48-51). All these approaches could

\section{REFERENCES}

1. Hillestad LK. Acute Promyelocytc Leukemia. Acta Med Scand (1957) 159 (3):189-94. doi: 10.1111/j.0954-6820.1957.tb00124.x

2. Bernard J, Weil M, Boiron M, Jacquillat C, Flandrin G, Gemon M-F. Acute Promyelocytic Leukemia: Results of Treatment by Daunorubicin. Blood (1973) 41(4):489-96. doi: 10.1182/blood.V41.4.489.489

3. Sanz MA, Jarque I, Martín G, Lorenzo I, Martínez J, Rafecas J, et al. Acute promyelocytic leukemia. Therapy results and prognostic factors. Cancer (1988) 61(1):7-13. doi: 10.1002/1097-0142(19880101)61:1<7::AIDCNCR2820610103>3.0.CO;2-6 pave the way for completely non-chemotherapy approaches in the high risk and relapse settings as well.

Over the last few decades, APL has transformed from being the "most malignant form of acute leukemia" to the "most curable form of acute leukemia" (54). Other than development of non-chemotherapy approaches, the current controversies in this field include optimal management of early deaths related to coagulopathy (like the role of recombinant thrombomodulin), the optimal dosing of ATRA and ATO, the optimal therapy for high-risk APL, the role for intrathecal prophylaxis, the role of prophylactic corticosteroids during induction therapy, and the need for maintenance therapy after consolidation $(55,56)$. Limitations of the present review are that we have not covered these controversies in the management of APL other than the non-chemotherapy approaches and also that we did not have a pre-defined search strategy for literature review.

\section{AUTHOR CONTRIBUTIONS}

UK wrote the manuscript. VM conceptualized and reviewed the manuscript. All authors contributed to the article and approved the submitted version.

\section{FUNDING}

Uday Kulkarni is supported by an early career fellowship program of DBT Wellcome India Alliance (IA/CPHE/17/1/ 503351), New Delhi, India. Vikram Mathews is supported by the senior fellowship program of the DBT Wellcome India Alliance (IA/CPHS/18/1/503930).

4. Mathews V, Chendamarai E, George B, Viswabandya A, Srivastava A. Treatment of acute promyelocytic leukemia with single-agent arsenic trioxide. Mediterr J Hematol Infect Dis (2011) 3(1):e2011056. doi: 10.4084/ mjhid.2011.056

5. Castaigne S, Chomienne C, Daniel MT, Ballerini P, Berger R, Fenaux P, et al. All-trans retinoic acid as a differentiation therapy for acute promyelocytic leukemia. I. Clinical results. Blood (1990) 76(9):1704-9. doi: 10.1182/ blood.V76.9.1704.1704

6. Muindi J, Frankel SR, Miller WH, Jakubowski A, Scheinberg DA, Young CW, et al. Continuous treatment with all-trans retinoic acid causes a progressive reduction in plasma drug concentrations: implications for relapse and 
retinoid "resistance" in patients with acute promyelocytic leukemia. Blood (1992) 79(2):299-303. doi: 10.1182/blood.V79.2.299.bloodjournal792299

7. De Botton S, Dombret H, Sanz M, Miguel JS, Caillot D, Zittoun R, et al. Incidence, clinical features, and outcome of all trans-retinoic acid syndrome in 413 cases of newly diagnosed acute promyelocytic leukemia. The European APL Group. Blood (1998) 92(8):2712-8. doi: 10.1182/ blood.V92.8.2712.420k03_2712_2718

8. Fenaux P, Chastang C, Chevret S, Sanz M, Dombret H, Archimbaud E, et al. A randomized comparison of all transretinoic acid (ATRA) followed by chemotherapy and ATRA plus chemotherapy and the role of maintenance therapy in newly diagnosed acute promyelocytic leukemia. The European APL Group. Blood (1999) 94(4):1192-200. doi: 10.1182/blood.V94.4.1192

9. Sanz MA, Martín G, Rayón C, Esteve J, González M, Díaz-Mediavilla J, et al. A modified AIDA protocol with anthracycline-based consolidation results in high antileukemic efficacy and reduced toxicity in newly diagnosed PML/ RARalpha-positive acute promyelocytic leukemia. PETHEMA group. Blood (1999) 94(9):3015-21. doi: 10.1182/blood.V94.9.3015

10. Sanz MA, Martín G, González M, León A, Rayón C, Rivas C, et al. Risk-adapted treatment of acute promyelocytic leukemia with all-trans-retinoic acid and anthracycline monochemotherapy: a multicenter study by the PETHEMA group. Blood (2004) 103(4):1237-43. doi: 10.1182/blood-2003-07-2462

11. Lo-Coco F, Avvisati G, Vignetti M, Breccia M, Gallo E, Rambaldi A, et al. Front-line treatment of acute promyelocytic leukemia with AIDA induction followed by risk-adapted consolidation for adults younger than 61 years: results of the AIDA-2000 trial of the GIMEMA Group. Blood (2010) 116 (17):3171-9. doi: 10.1182/blood-2010-03-276196

12. Shen ZX, Chen GQ, Ni JH, Li XS, Xiong SM, Qiu QY, et al. Use of arsenic trioxide (As2O3) in the treatment of acute promyelocytic leukemia (APL): II. Clinical efficacy and pharmacokinetics in relapsed patients. Blood (1997) 89 (9):3354-60. doi: 10.1182/blood.V89.9.3354

13. Niu C, Yan H, Yu T, Sun HP, Liu JX, Li XS, et al. Studies on treatment of acute promyelocytic leukemia with arsenic trioxide: remission induction, follow-up, and molecular monitoring in 11 newly diagnosed and 47 relapsed acute promyelocytic leukemia patients. Blood (1999) 94(10):3315-24. doi: 10.1182/ blood.V94.10.3315.422k16_3315_3324

14. Jolliffe DM. A history of the use of arsenicals in man. J R Soc Med (1993) 86 (5):287-9.

15. Zhang TD. [Treatment of acute granulocytic leukemia with "Ai ling No. 1"clinical analysis and experimental research]. Zhong Xi Yi Jie He Za Zhi (1984) 4(1):19-20.

16. Soignet SL, Maslak P, Wang ZG, Jhanwar S, Calleja E, Dardashti LJ, et al. Complete remission after treatment of acute promyelocytic leukemia with arsenic trioxide. N Engl J Med (1998) 339(19):1341-8. doi: 10.1056/ NEJM199811053391901

17. Ravandi F, Kantarjian H. Time to abandon traditional chemotherapy for acute promyelocytic leukaemia? Lancet Oncol (2015) 16(13):1274-5. doi: 10.1016/ S1470-2045(15)00210-7

18. Burnett AK, Russell NH, Hills RK, Bowen D, Kell J, Knapper S, et al. Arsenic trioxide and all-trans retinoic acid treatment for acute promyelocytic leukaemia in all risk groups (AML17): results of a randomised, controlled, phase 3 trial. Lancet Oncol (2015) 16(13):1295-305. doi: 10.1016/S1470-2045 (15)00193-X

19. Platzbecker U, Avvisati G, Cicconi L, Thiede C, Paoloni F, Vignetti M, et al. Improved Outcomes With Retinoic Acid and Arsenic Trioxide Compared With Retinoic Acid and Chemotherapy in Non-High-Risk Acute Promyelocytic Leukemia: Final Results of the Randomized Italian-German APL0406 Trial. J Clin Oncol (2017) 35(6):605-12. doi: 10.1200/ JCO.2016.67.1982

20. Bankar A, Korula A, Kulkarni UP, Devasia AJ, Na F, Lionel S, et al. Resource utilization and cost effectiveness of treating acute promyelocytic leukaemia using generic arsenic trioxide. Br J Haematol (2020) 189(2):269-78. doi: 10.1111/bjh. 16343

21. Mathews V, Chandy M, Srivastava A. Arsenic trioxide in the management of acute promyelocytic leukaemia. Natl Med J India (2001) 14(4):215-22.

22. Mathews V, Balasubramanian P, Shaji RV, George B, Chandy M, Srivastava A. Arsenic trioxide in the treatment of newly diagnosed acute promyelocytic leukemia: a single center experience. Am J Hematol (2002) 70(4):292-9. doi: 10.1002/ajh.10138
23. Mathews V, George B, Lakshmi KM, Viswabandya A, Bajel A, Balasubramanian P, et al. Single-agent arsenic trioxide in the treatment of newly diagnosed acute promyelocytic leukemia: durable remissions with minimal toxicity. Blood (2006) 107(7):2627-32. doi: 10.1182/blood-200508-3532

24. Mathews V, George B, Chendamarai E, Lakshmi KM, Desire S, Balasubramanian P, et al. Single-agent arsenic trioxide in the treatment of newly diagnosed acute promyelocytic leukemia: long-term follow-up data. $J$ Clin Oncol (2010) 28(24):3866-71. doi: 10.1200/JCO.2010.28.5031

25. Mathews V, Thomas M, Srivastava VM, George B, Srivastava A, Chandy M. Impact of FLT3 mutations and secondary cytogenetic changes on the outcome of patients with newly diagnosed acute promyelocytic leukemia treated with a single agent arsenic trioxide regimen. Haematologica (2007) 92(7):994-5. doi: 10.3324/haematol.10802

26. Ghavamzadeh A, Alimoghaddam K, Rostami S, Ghaffari SH, Jahani M, Iravani $\mathrm{M}$, et al. Phase II study of single-agent arsenic trioxide for the front-line therapy of acute promyelocytic leukemia. J Clin Oncol (2011) 29 (20):2753-7. doi: 10.1200/JCO.2010.32.2107

27. Powell BL, Moser B, Stock W, Gallagher RE, Willman CL, Stone RM, et al. Arsenic trioxide improves event-free and overall survival for adults with acute promyelocytic leukemia: North American Leukemia Intergroup Study C9710. Blood (2010) 116(19):3751-7. doi: 10.1182/blood-2010-02-269621

28. Lallemand-Breitenbach V, Guillemin M-C, Janin A, Daniel M-T, Degos L, Kogan SC, et al. Retinoic Acid and Arsenic Synergize to Eradicate Leukemic Cells in a Mouse Model of Acute Promyelocytic Leukemia. J Exp Med (1999) 189(7):1043-52. doi: 10.1084/jem.189.7.1043

29. Jing Y, Wang L, Xia L, Chen G, Chen Z, Miller WH, et al. Combined effect of all-trans retinoic acid and arsenic trioxide in acute promyelocytic leukemia cells in vitro and in vivo. Blood (2001) 97(1):264-9. doi: 10.1182/ blood.V97.1.264

30. Shen ZX, Shi ZZ, Fang J, Gu BW, Li JM, Zhu YM, et al. All-trans retinoic acid/ As2O3 combination yields a high quality remission and survival in newly diagnosed acute promyelocytic leukemia. Proc Natl Acad Sci U S A (2004) 101 (15):5328-35. doi: 10.1073/pnas.0400053101

31. Iland HJ, Bradstock K, Supple SG, Catalano A, Collins M, Hertzberg M, et al. All-trans-retinoic acid, idarubicin, and IV arsenic trioxide as initial therapy in acute promyelocytic leukemia (APML4). Blood (2012) 120(8):1570-80. doi: 10.1182/blood-2012-02-410746

32. Sanz MA, Fenaux P, Tallman MS, Estey EH, Löwenberg B, Naoe T, et al. Management of acute promyelocytic leukemia: updated recommendations from an expert panel of the European LeukemiaNet. Blood (2019) 133 (15):1630-43. doi: 10.1182/blood-2019-01-894980

33. Cicconi L, Platzbecker U, Avvisati G, Paoloni F, Thiede C, Vignetti M, et al. Long-term results of all-trans retinoic acid and arsenic trioxide in non-highrisk acute promyelocytic leukemia: update of the APL0406 Italian-German randomized trial. Leukemia (2020) 34(3):914-8. doi: 10.1038/s41375-0190589-3

34. Russell N, Burnett A, Hills R, Betteridge S, Dennis M, Jovanovic J, et al. Attenuated arsenic trioxide plus ATRA therapy for newly diagnosed and relapsed APL: long-term follow-up of the AML17 trial. Blood (2018) 132 (13):1452-4. doi: 10.1182/blood-2018-05-851824

35. Iland HJ, Collins M, Bradstock K, Supple SG, Catalano A, Hertzberg M, et al. Use of arsenic trioxide in remission induction and consolidation therapy for acute promyelocytic leukaemia in the Australasian Leukaemia and Lymphoma Group (ALLG) APML4 study: a non-randomised phase 2 trial. Lancet Haematol (2015) 2(9):e357-66. doi: 10.1016/S2352-3026(15)00115-5

36. Ravandi F, Estey E, Jones D, Faderl S, O’Brien S, Fiorentino J, et al. Effective treatment of acute promyelocytic leukemia with all-trans-retinoic acid, arsenic trioxide, and gemtuzumab ozogamicin. J Clin Oncol (2009) 27(4):504-10. doi: 10.1200/JCO.2008.18.6130

37. Abaza Y, Kantarjian H, Garcia-Manero G, Estey E, Borthakur G, Jabbour E, et al. Long-term outcome of acute promyelocytic leukemia treated with alltrans-retinoic acid, arsenic trioxide, and gemtuzumab. Blood (2017) 129 (10):1275-83. doi: 10.1182/blood-2016-09-736686

38. Lancet JE, Moseley AB, Coutre SE, DeAngelo DJ, Othus M, Tallman MS, et al. A phase 2 study of ATRA, arsenic trioxide, and gemtuzumab ozogamicin in patients with high-risk APL (SWOG 0535). Blood Adv (2020) 4(8):1683-9. doi: 10.1182/bloodadvances.2019001278 
39. Gill H, Yim R, Lee HKK, Mak V, Lin S-Y, Kho B, et al. Long-term outcome of relapsed acute promyelocytic leukemia treated with oral arsenic trioxidebased reinduction and maintenance regimens: A 15-year prospective study. Cancer (2018) 124(11):2316-26. doi: 10.1002/cncr.31327

40. Zhu H-H, Wu D-P, Du X, Zhang X, Liu L, Ma J, et al. Oral arsenic plus retinoic acid versus intravenous arsenic plus retinoic acid for non-high-risk acute promyelocytic leukaemia: a non-inferiority, randomised phase 3 trial. Lancet Oncol (2018) 19(7):871-9. doi: 10.1016/S1470-2045(18)30295-X

41. Ravandi F, Koumenis I, Johri A, Tallman M, Roboz GJ, Strickland S, et al. Oral arsenic trioxide ORH-2014 pharmacokinetic and safety profile in patients with advanced hematologic disorders. Haematologica (2020) 105(6):1567-74. doi: 10.3324/haematol.2019.229583

42. Chendamarai E, Ganesan S, Alex AA, Kamath V, Nair SC, Nellickal AJ, et al. Comparison of Newly Diagnosed and Relapsed Patients with Acute Promyelocytic Leukemia Treated with Arsenic Trioxide: Insight into Mechanisms of Resistance. PloS One (2015) 10(3):e0121912. doi: 10.1371/journal.pone.0121912

43. Ganesan S, Alex AA, Chendamarai E, Balasundaram N, Palani HK, David S, et al. Rationale and efficacy of proteasome inhibitor combined with arsenic trioxide in the treatment of acute promyelocytic leukemia. Leukemia (2016) 30(11):2169-78. doi: 10.1038/leu.2016.227

44. Kulkarni U, Ganesan S, Alex AA, Palani H, David S, Balasundaram N, et al. A phase II study evaluating the role of bortezomib in the management of relapsed acute promyelocytic leukemia treated upfront with arsenic trioxide. Cancer Med (2020) 9(8):2603-10. doi: 10.1002/cam4.2883

45. Cassinat B, Zassadowski F, Ferry C, Llopis L, Bruck N, Lainey E, et al. New Role for Granulocyte Colony-Stimulating Factor-Induced Extracellular Signal-Regulated Kinase 1/2 in Histone Modification and Retinoic Acid Receptor $\alpha$ Recruitment to Gene Promoters: Relevance to Acute Promyelocytic Leukemia Cell Differentiation. Mol Cell Biol (2011) 31 (7):1409-18. doi: 10.1128/MCB.00756-10

46. Zassadowski F, Pokorna K, Ferre N, Guidez F, Llopis L, Chourbagi O, et al. Lithium chloride antileukemic activity in acute promyelocytic leukemia is GSK-3 and MEK/ERK dependent. Leukemia (2015) 29(12):2277-84. doi: 10.1038/leu.2015.159

47. Balasundaram N, Ganesan S, Palani HK, Alex AA, David S, Korula A, et al. Metabolic Rewiring Drives Resistance to Arsenic Trioxide in Acute Promyelocytic Leukemia. Blood (2016) 128(22):3956-6. doi: 10.1182/ blood.V128.22.3956.3956

48. dos Santos GAS, e Lima RSA, Pestana CR, Lima ASG, Scheucher PS, Thomé $\mathrm{CH}$, et al. $(+) \alpha$-Tocopheryl succinate inhibits the mitochondrial respiratory chain complex I and is as effective as arsenic trioxide or ATRA against acute promyelocytic leukemia in vivo. Leukemia (2012) 26(3):451-60. doi: 10.1038/ leu.2011.216
49. Niu X, Wang G, Wang Y, Caldwell JT, Edwards H, Xie C, et al. Acute Myeloid Leukemia Cells Harboring MLL Fusion Genes or with the Acute Promyelocytic Leukemia Phenotype Are Sensitive to the Bcl-2selective Inhibitor ABT-199. Leukemia (2014) 28(7):1557-60. doi: 10.1038/ leu. 2014.72

50. Leiva M, Moretti S, Soilihi H, Pallavicini I, Peres L, Mercurio C, et al. Valproic acid induces differentiation and transient tumor regression, but spares leukemia-initiating activity in mouse models of APL. Leukemia (2012) 26 (7):1630-7. doi: 10.1038/leu.2012.39

51. Bastie J-N, Balitrand N, Guillemot I, Chomienne C, Delva L. Cooperative action of $1 \alpha, 25$-dihydroxyvitamin D3 and retinoic acid in NB4 acute promyelocytic leukemia cell differentiation is transcriptionally controlled. Exp Cell Res (2005) 310(2):319-30. doi: 10.1016/j.yexcr. 2005.08.001

52. Yaguchi M, Miyazawa K, Katagiri T, Nishimaki J, Kizaki M, Tohyama K, et al. Vitamin $\mathrm{K} 2$ and its derivatives induce apoptosis in leukemia cells and enhance the effect of all- trans retinoic acid. Leukemia (1997) 11(6):779-87. doi: $10.1038 /$ sj.leu.2400667

53. Orfali N, O'Donovan TR, Nyhan MJ, Britschgi A, Tschan MP, Cahill MR, et al. Induction of autophagy is a key component of all-trans-retinoic acidinduced differentiation in leukemia cells and a potential target for pharmacological modulation. Exp Hematol (2015) 43(9):781-93.e2. doi: 10.1016/j.exphem.2015.04.012

54. Thomas X. Acute Promyelocytic Leukemia: A History over 60 Years-From the Most Malignant to the most Curable Form of Acute Leukemia. Oncol Ther (2019) 7(1):33-65. doi: 10.1007/s40487-018-0091-5

55. Osman AEG, Anderson J, Churpek JE, Christ TN, Curran E, Godley LA, et al. Treatment of Acute Promyelocytic Leukemia in Adults. J Oncol Pract (2018) 14(11):649-57. doi: 10.1200/JOP.18.00328

56. Sanz MA, Montesinos P. Advances in the management of coagulopathy in acute promyelocytic leukemia. Thromb Res (2020) 191(Suppl 1):S63-7. doi: 10.1016/S0049-3848(20)30399-6

Conflict of Interest: The authors declare that the research was conducted in the absence of any commercial or financial relationships that could be construed as a potential conflict of interest.

Copyright $\odot 2021$ Kulkarni and Mathews. This is an open-access article distributed under the terms of the Creative Commons Attribution License (CC BY). The use, distribution or reproduction in other forums is permitted, provided the original author (s) and the copyright owner(s) are credited and that the original publication in this journal is cited, in accordance with accepted academic practice. No use, distribution or reproduction is permitted which does not comply with these terms. 